\title{
Filipino Teachers of English and Native English Teachers: Learners' Perceptions
}

\author{
Shigeru Ozaki \\ Doshisha University, Japan \\ E-mail: shigeruozaki@hotmail.com
}

Cite this article as: Ozaki, S. (2021). Filipino Teachers of English and Native English Teachers: Learners' Perceptions. International Journal of Second and Foreign Language Education, 1(1), 10-16. https://doi.org/10.33422/ijsfle.v1i1.59

\begin{abstract}
Since learning English from Filipino Teachers of English (FTEs) has gained popularity, this research investigated learners' perceptions of the difference between FTEs and native English teachers (NETs) by conducting semi-structured interviews at two English language schools that have both FTEs and NETs. Many learners felt that FTEs were better at explaining grammar explicitly and comprehensibly, while others said that they could better improve their listening and pronunciation skills with NETs since they spoke faster and with more phonological changes and colloquial expressions. However, some felt more comfortable talking to FTEs, since their English was easier to understand. Additionally, some believed that the pronunciation of NETs was better simply because they were native speakers. One of the schools had an NET who was trained in teaching how to articulate English phonemes. His students noted that NETs were better at teaching pronunciation. However, this view was not shared by learners from other schools. Some reported that FTEs were easier to befriend, though this was because the learners and their teachers belonged to similar age groups. Some mentioned that FTEs, who are also English learners, were more passionate about teaching, understanding, and helping learners, while only one student claimed that NTEs were more serious teachers. A few were more motivated by NETs solely because they admired native speakers. In summary, the participants of this study generally considered FTEs to be better, although some individual differences were observed. The results suggest the importance of teacher training and teachers' experience in learning a second/foreign language.
\end{abstract}

Keywords: grammar, pronunciation, language learning experience, passion, teacher training

\section{Introduction}

Learning English in the Philippines or learning the language from Filipino teachers of English (FTEs) has become increasingly popular (Haisa, 2016) due to its low cost (Brock, 2015; Haisa, 2016; McGeown, 2012) and Filipinos' high English proficiency (Chavez, 2014; Ozaki, 2011; Ozaki, 2017; Pearson, 2013). Those who are wishing to learn English have shifted to the Philippines from Englishspeaking countries such as the UK, the US, Canada, Australia, and New Zealand (McGeown, 2012). In China, the Philippines offers a low-cost solution to the growing demand for English teachers (Lijuan, 2019). In July 2008, the South Korean government stated that Filipino teachers of English (FTEs) would be granted visas to teach English in the country, replacing their counterparts from Western countries (The Philippines EFL, n.d.). Furthermore, many international online English schools are now based in the Philippines (Keitel, 2009).

Although some research (Kobayashi, 2008; Guzman, et al., 2006; Haisa, 2016; Haisa \& Watanabe, 2013; Ozaki, 2011; Ozaki, 2017; Yeh, 2019) has been conducted on the learning of English in the

(C) The Author(s). 2021 Open Access. This article is distributed under the terms of the Creative Commons Attribution 4.0 International License, which permits unrestricted use, distribution, and redistribution in any medium, provided that the original author(s) and source are credited. 
Philippines and/or on FTEs, there has only been a small number of empirical studies (Kobayashi, 2008; Ozaki, 2017) related to the attributes of FTEs. Although her focus was on the study of English in the Philippines in general rather than on FTEs specifically, Kobayashi (2008) found that students from Taiwan generally considered FTEs to be good teachers, while stating that their English pronunciation was not very good. This matches Ozaki's (2017) findings. Haisa (2016) found that Japanese learners of English regarded native English speakers' language as their ideal model both before and after their learning experience in the Philippines, although they showed a favorable and generous attitude toward Filipino English after having studied English in the Philippines. However, Ozaki (2011) claimed that FTEs have the attributes of both non-native English teachers (NNETs) and NETs; that is, the possession of all three types of expertise of language teachers: "skills in the target language," "explicit knowledge about the language," and "pedagogic skills" (Medgyes, 1994, p. 57). Although NNETs are typically inferior to NETs in the first category, FTEs' English proficiency tends to be very high since they are often educated in English and use it not only as an official language but also a second language in their daily lives. Ozaki's (2011) discussion, however, was not based on empirical evidence. Only one study (Ozaki, 2017) had, as its whole purpose, the empirical investigation of how learners perceive FTEs in comparison with NETs. His study adopted the three types of expertise suggested by Medgyes (1994), as its theoretical framework. In his research, English learners from various countries, who had come to the Philippines to learn English, were asked about their perceptions of FTEs. This is because students are more likely to judge their teachers based on their perceptions than by objective measurements. The results of this questionnaire research showed that learners evaluated FTEs highly in all the three criteria, although they assessed FTEs' pronunciation and speaking skills only slightly lower than other skills such as listening, reading, and writing, which matches what was found by Guzman, et al. (2006) and Kobayashi (2008). These results generally support Ozaki's (2011) assumption that FTEs possess all three types of expertise of language teachers suggested by Medgyes (1994). It is particularly noteworthy that their language skills were highly evaluated, although language skills are generally regarded as a weakness of NNETs, which is one of the main reasons why learners prefer to be taught by NETs. A drawback of the research conducted by Ozaki (2017) is that it did not provide detailed information on the learners' views because it adopted questionnaires that mostly consisted of multiple-choice questions. In light of this, the current study utilized interviews to obtain more in-depth information concerning learners' perceptions. The following section explains the methods adopted in this study.

\section{Methods}

\section{Participants}

I conducted this research at two English language schools in Pampanga, the Philippines, interviewing 16 students between the ages of 19 and 45: seven Japanese (four females, three males), three Taiwanese (one female, two males), three Vietnamese (two females, one male), two Koreans (two females), and one Chinese (female). The students had been learning English in the Philippines for between two weeks to six months at the time of the study, and most of them were intermediate learners.

\section{Instrument}

I adopted semi-structured interviews to obtain in-depth information concerning learners' perceptions of the differences between FTEs and NETs for the following criteria based on the literature review (Kobayashi, 2008; Medgyes, 1994; Ozaki, 2011; Ozaki, 2017): English language skills, especially in 
terms of pronunciation and speaking; explicit knowledge of the language; and skills in teaching English. Furthermore, the participants were asked to mention other differences they had noticed. They were also requested to provide personal information such as nationality, age, gender, length of their study in the Philippines, level of English at school, and English proficiency test scores. The interviews were conducted in English or Japanese, depending on the participants' English proficiency and nationalities. Before the interviews, I reconfirmed that they were willing to participate in the study and that they consented to the publishing of the results. It should be noted that this confirmation, as well as information about the content of the interviews, had already been shared with the students by the schools' management prior to my visit. The following questions were prepared before the interviews:

1) Are there any differences between native English teachers and Filipino English teachers regarding language skills, such as reading, writing, listening, speaking, and pronunciation; knowledge of the English language, such as grammar and pronunciation of English sounds and words; teaching skills; and other aspects?

2) What are native English teachers and Filipino English teachers' good points and bad points?

During the interview process, I added further questions, depending on the students' answers, to the above two questions. It should be noted that I occasionally changed the vocabulary of the questions depending on the English proficiency of the interviewees. Furthermore, when Japanese students' English proficiency was not high enough for them to express themselves well, the interview was conducted in Japanese.

\section{Results}

This section presents the results for the following criteria: English language skills, explicit knowledge of the language, skills in teaching English, and other differences. It should be noted that the second and third criteria were combined in this section because it was revealed that good teaching skills stemmed directly from explicit knowledge of the language. The 16 students interviewed were numbered from S1 to S16 in the results section. No particular tendencies based on personal backgrounds were found.

\section{English Language Skills}

Nine students (S1, S3, S7, S8, S9, S10, S13, S14, S15) said that the accents of NETs were better than those of FTEs, although this was based on their assumption that native-speaker accents are perfect rather than a detailed analysis of the pronunciations of both NETs and FTEs. None of the students referred to the fact that there are various accents among native varieties of English, even within a single country. Furthermore, six students (S1, S2, S4, S6, S13, S16) thought that they could improve their listening and pronunciation skills more easily with NETs than with FTEs, because NETs spoke more quickly with more phonological changes and made more use of colloquial or slang expressions. This statement is based on NETs' language skills rather than their teaching skills. However, five students (S2, S6, S12, S14, S16) felt more comfortable talking to FTEs because their English was easier to understand, owing to a lack of the above attributes.

\section{Explicit Knowledge of the Language and Teaching Skills}

Ten students (S1, S2, S4, S5, S7, S8, S10, S11, S13, S15) commented that FTEs were better at explaining grammar explicitly and more comprehensibly. However, three students (S1, S4, S5) at one of the schools noted that one NET possessed a particularly good knowledge of phonetics and was better 
than FTEs at teaching the pronunciation of English phonemes. This NET told me that he had received training to teach pronunciation at the school where he had obtained his TESOL certificate. No such claim was raised by students at the other school, although one student (S16) did comment that NETs corrected his pronunciation more frequently than FTEs. In this case, however, they only repeated the problematic pronunciations and did not teach the student how to properly articulate English phonemes, instead asking them to also repeat their problematic pronunciations. Furthermore, another student (S11) at this school stated that FTEs more frequently corrected his pronunciation by utilizing their expert knowledge of phonetics. One student (S4) noted that NETs were better at explaining the meanings of words, while another student (S8) reported that FTEs knew more teaching methods. Two students (S11, S16) said that FTEs could teach them how to improve their English proficiency test scores.

\section{Other Findings}

Three students (S2, S14, S15) stated that FTEs were easier to befriend, although two (S14, S15) added that this was because they were similar in age. One student (S10) reported that FTEs were better in general because they were also English learners and could therefore understand students better. Three students (S1, S4, S11) claimed that FTEs taught them more about culture than NETs, while another three (S4, S12, S15) claimed the opposite. Two (S3, S9) reported that FTEs were more passionate in their teaching and helped students more, and another (S4) noted that FTEs taught her until she could understand, without giving up too easily. Another student (S8) also claimed that FTEs made a greater effort to understand students. In contrast, one student (S15) stated that NETs taught more seriously. According to one student (S12), both FTEs and NTEs occasionally arrived late to class. In these cases, she claimed that the NTE would never apologize, while the FTE always would. Two students (S4, S10) commented that NETs motivated them more. One (S4) explained that this was because she wanted to be able to speak like a native English speaker, while the other (S10) said that it was because she wanted to work in the USA. Another student (S16) thought that NETs were better because she admired British and American English and wanted to go to the US and the UK. Finally, one student (S15) stated that NETs were simply better because they were native English speakers.

\section{Discussion}

The results of this study offer a wider variety and more in-depth information than Ozaki's (2017) study, which was conducted based on questionnaires. The majority of students believed that NETs were better than FTEs, particularly in terms of pronunciation, which matches Kobayashi (2008) and Ozaki's (2017) findings. However, this study revealed that such an idea stemmed from students' belief that native English speakers' pronunciations were perfect, rather than from a detailed analysis of the English of NETs and FTEs. No participants mentioned that diverse accents exist among native varieties of English, or that there is no standard English accent (Smith, 1992; Trudgill \& Hannah, 1994). One student also claimed that NETs were better only because they were native speakers of the target language. Others said that they admired American or British English and wanted to speak it. Haisa's (2016) found this tendency too: His study revealed that Japanese university students who learned English in the Philippines regarded native speakers' English as their model both after and before their study trips. In his study, one of the participants stated that his goal was to attain native-like pronunciation since he believed that the closer his pronunciation was to that of native English speakers, the more easily people would be able to understand him. However, “... native-speaker accents are not necessarily the most intelligible or appropriate accents when a non-native speaker is communicating..." 
(British Council, 2011, p. 1). The unique phonological features of Filipino English, which derive from the influences of both their native languages and American English (Tayao, 2008), are not necessarily a drawback regarding the intelligibility of FTEs' English. In fact, some participants of this study said that it was easier or more comfortable to speak to FTEs because their English was easier to understand. In English-speaking countries, many immigrants from a range of countries speak English with accents derived from their native languages, and they have no difficulty communicating with both native and other non-native English speakers. However, FTEs should be aware that they do not speak English as quickly as NTEs and their English is simpler than NTEs' in terms of both phonological changes and vocabulary, and that they should compensate for these gaps by using audio or visual materials in which their students could be exposed to native varieties of English. NTEs should also utilize such materials to have students listen to different native varieties of English and more naturally spoken English since ESL teachers often use foreigner talk by speaking slowly with simple grammar and vocabulary. If they continue speaking slowly in simple English, students may never be able to understand the target language spoken naturally by other native speakers.

The majority of respondents considered FTEs to be better in terms of explaining grammar. This strength likely stems from the fact that Filipinos learn English as a second language rather than a mother tongue, and they learn grammar consciously and systematically through formal instruction. In contrast, native speakers usually acquire grammar subconsciously through natural circumstances. This difference likely explains why FTEs were more highly evaluated by students regarding explicit knowledge of the language and teaching skills. They were also considered better at teaching how to improve English proficiency test scores, due to their own experience taking the tests as second-language learners. One NET was described as being good at teaching the articulation of English phonemes based on his knowledge of phonetics acquired through his TESOL teacher training. However, other NETs were said to repeat problematic pronunciations and had students repeat them to correct their pronunciation. Such a method of repetition often does not work because students cannot correctly hear and produce the sounds in the same way as the NETs; if they could, they would be able to acquire native-like pronunciation without much difficulty. This suggests the importance of teacher training, which enables NETs to obtain explicit knowledge of their language and ways to teach it comprehensibly. Such teacher training would lead them to be better teachers, adding to their advantageous position regarding language skills along with students' admiration for native English speakers.

Some mentioned that FTEs were more passionate about teaching as well as understanding and helping students. This may be because they had also learned English as non-native speakers, as one of the students explained. In fact, many of the reported advantages of learning from FTEs stemmed from the fact that they had learned English as a second language.

Some insisted that NETs were better; however, this was not because of their proficiency as teachers, but due to students' admiration for native English speakers and English-speaking countries.

\section{Conclusion}

This study investigated the differences between NETs and FTEs by adopting semi-structured interviews. It found that learners generally considered the latter better than the former, even though there were some individual differences among both respondents and teachers. While the advantages of FTEs derived from their experiences as learners of English as a second language, the advantages of NETs typically stemmed from their status as native speakers and students' admiration for English-speaking countries, especially with respect to pronunciation. However, one teacher was highly appreciated due to his teacher training. These results suggest that there are two primary characteristics of language teachers 
that students appreciate, namely, having had teacher training, and having learned a second/foreign language. In order to be evaluated highly as a language teacher, NETs should improve their explicit knowledge of grammar and phonetics, as well as the teaching skills that result from this expert knowledge. Furthermore, it would also be beneficial for NETs to learn a second or foreign language themselves to better understand language teaching, language learning, and learners.

Although the results of this research indicated the superiority of FTEs, the sample size was too small to generalize this tendency, and some individual differences were observed. Thus, if the same research was conducted among a larger number of participants and language institutes, the results may differ. Furthermore, investigation of teachers' perspectives, in addition to learners' perceptions, might significantly contribute to this field. Another possible area of future research would be the examination of the differences in students' learning progress when taught by NETs and FTEs, since existing research has only examined learners' perceptions of the differences between them, rather than the educational outcomes.

\section{References}

British Council. (2011). Global English and the teaching of pronunciation. Teaching English. http://www.teachingenglish.org.uk/article/global-english-teaching-pronunciation

Brock, A. (2015). Philippines attracts English learners on a budget. VOA. budget/2706062.html

Chavez, A. (2014, January 10). What Asia can learn from Philippines about English education. Huffington Post. https://www.huffpost.com/entry/what-asia-can-learn-from- b_ 4572991

Guzman, A. B., Albela, E. J. A., Nieto, D. R. D., Ferrer, J. B. F., S, R. N. (2006). Asia Pacific Education Review, $7(2), 152-161$.

Haisa, A. (2016). Studying English in the Philippines and its influence on language attitudes: Analysis of interview data from Japanese learners. Ryuugaku Kouryuu, 62, pp. 7-10.

Haisa, A. \& Watanabe, Y. (2013). Language attitudes of Japanese learners who are planning to study English in the Philippines. The Journal of Sagami Women's University, 77, pp. 1-7.

Keitel, R. S. (2009). Innovation in borderless distance learning of English. Paper presented at the 13th UNESCOAPEID International Conference World Bank-KERIS High Level Seminar on ICT in Education.

Kobayashi, I. (2008). They speak 'incorrect' English. Understanding- Understanding Taiwanese learners' views on L2 varieties of English. Philippine Journal of Linguistics, 39, 81-98.

Lijuan, Y. (2019, January 16). Philippines offers low-cost solution to China's growing English teacher demand. Global Times. https://www.globaltimes.cn/content/1135986.shtml

McGeown, K. (2012). The Philippines: The world's budget English teacher. http://www.bbc.com/news/business20066890.news/business-20066890

Medgyes, P. (1994). The non-native teacher. London: Macmillan Publishers.

Ozaki, S. (2011). Learning English as an international lingua franca in a semi-English-speaking country: The Philippines. Asian EFL Journal. Professional Teaching Articles, 53, pp. 51-60.

Ozaki, S. (2017). Learners' perceptions of Filipino EFL teacher expertise. Journal of Education and Social Sciences, 7, pp. 123-128. https://www.jesoc.com/wp-content/ uploads/ 2017/ 11/ JESOC7 55.pdf

Pearson English Business Solutions. (2013). Heightened urgency for business English in an increasingly global workforce. San Francisco, CA: Pearson Business English Solutions.

Smith, L. E. (1992). Spread of English and issues of intelligibility. In B. Kachru (Ed.), The other tongue: English across cultures (pp. 75-90). Urbana: University of Illinois Press.

Tayao, M. L. G. (2008). A lectal description of the phonological features of Philippine English. In Ma. L. S. Bautista \& K. Bolton (Eds.), Philippine English: Linguistic and literary perspectives (Asian Englishes today) (pp. 157-174). Hong Kong: Hong Kong University Press.

The Philippines EFL: A rapidly growing market. (n.d.). EFL-Law. http://www.efl-law.com/Philippines.php 
Trudgill, P. \& Hannah, J. (1994). International English: A guide to the varieties of standard English. New York: Edward Arnold.

Yeh, A. (2019). Problematizing the commodification of ESL teaching in the Philippines: Mediating expectations, norms and identity(ies). Journal of English as an International Language, 14, 92-118. 